\title{
Students' experiences and acceptance of emergency online learning due to COVID-19
}

\author{
Marija Marković, Dragana Pavlović, Anastasija Mamutović \\ Faculty of Philosophy, University of Niš, Serbia
}

\begin{abstract}
At the outbreak of the COVID-19 pandemic, higher education institutions around the world were compelled to bring forth suitable alternatives to secure continuity in the process of education. To gather data that would indicate the quality and efficiency of online teaching in higher education in south and south-eastern Serbia initiated at the outbreak of the pandemic and the state of emergency declared in March 2020, we conducted a research study to provide the necessary information from students attending undergraduate academic studies. The research was conducted in two phases. The first phase consisted of quantitative research conducted on a sample of 211 students. The data collected were processed by resorting to factor analysis to determine specific factors as a starting point for designing questions for the second research phase. The second phase was implemented by conducting semi-structured interviews on a sample of 61 students. The main intention was to determine key characteristics of the teaching process realised in the context of an emergency transition to the form of teaching which had not been prepared or resorted to beforehand. We identified certain specifics in this regard, as a starting point for improving existing practice.
\end{abstract}

\section{Implications for practice or policy:}

- It is necessary to secure a suitable level of institutional support, to maintain the quality of higher education in unforeseen social circumstances.

- It is necessary to adequately prepare for and support teachers and students in online teaching at both institutional and national level.

- To avoid adverse effects on individual students in the circumstances of online teaching, it is necessary to meet students' educational, social and emotional needs.

Keywords: online learning, COVID-19 pandemic, individual differences, factor analysis, semi-structured interviews

\section{Introduction}

Due to the state of emergency declared on the outbreak of the COVID-19 pandemic (hereinafter, the pandemic), higher education institutions faced a number of challenges caused by the transition to online teaching and learning (Aguilera-Hermida, 2020). Generally speaking, online education requires that a teacher renounces traditional teaching paradigms and embraces new teaching methods based on the efficient use of modern technologies (Herrera-Pavo, 2021; Lapitan et al., 2021). Online teaching requires that university professors acquire various technical skills and become a part of the institution's development process in terms of introducing and implementing quality online teaching (Fish \& Wickersham, 2009). Such transition can be demanding and time-consuming even under regular circumstances, and the fact that it took place in the context of the pandemic only adds to its original complexity. The research aim was to examine students' attitudes regarding the quality of emergency online teaching, its positive and negative aspects as well as the difficulties encountered in the process of implementation. At the outbreak of the pandemic, the Faculty of Philosophy at the Republic of Serbia's University of Niš took a couple of days to fully exchange traditional teaching for synchronous online teaching to preserve the continuity of education. The teachers resorted to synchronous online teaching by using digital tools such as Google Meet and Zoom as well as Google Classroom as an asynchronous addition to online teaching. At the time, this form of teaching was rare in higher education institutions in Serbia. More precisely, only 18 higher education institutions in Serbia had at least one accredited study programme for distance learning (Milićević et al., 2021). The aim was to examine how successful the faculty was at making this transition, to observe the directions of further development as well as general implications which could be reported from the findings. 


\section{Theoretical background}

Successful online teaching requires new methods of planning and teaching, interaction among the course participants and teachers' previous preparation and support for students (Crawford-Ferre \& Wiest, 2012). When it comes to designing an online course, the technology needs to be in line with students' diverse needs. Different ways of presenting the teaching content should be available (asynchronous and synchronous teaching activities, sharing the required teaching materials) as well as different ways of mutual communication (email, chat, webcam communication). Interaction among students is another important aspect of successful online teaching. Teachers are expected to structure and enable quality discussions, which requires both asynchronous and synchronous teaching methods to help create a learning community. It is, however, vital to educate students to use digital tools and technologies necessary for successful online interaction. Preparation and institutional support for teachers (to make the necessary technology available, to reduce their workload, to enable quality interaction among colleagues regarding online teaching experiences) comprise an important aspect of quality online teaching. Online teaching is a complex task that requires teachers' wholehearted engagement, which can be time-consuming and exhausting (Bolliger \& Wasilik, 2009; Tynan et al., 2015).

In addition to the individual characteristics of students, the characteristics of online teaching and the higher education institution correlate significantly with students' achievements in online courses (Money \& Dean, 2019). Dropping out of higher education is an even more pronounced problem in online teaching, which is why care should be taken that such teaching is sufficiently adapted to individual needs and sufficiently stimulating for those who attend it (Delnoij et al., 2020).

Students' attitudes towards emergency online learning as well as their motivation, self-efficiency and previous experiences of using digital tools affect their level of cognitive engagement and academic achievement (Aguilera-Hermida, 2020). The following four individual characteristics are predictors of students' academic achievement in online teaching: language skills (reading and writing); independent learning (suitable time management, structuring the time for tasks and assignments, setting the goals, selfdiscipline, and personal responsibility); motivation; and digital literacy (Kerr et al., 2006). The transition to online teaching is thus a complex process that requires serious planning and its success is influenced by a number of factors. This paper gives an overview of the quality of the transformation of the educational process in emergency situations when it is not possible to plan thoroughly and gives an insight into which characteristics higher education institutions should be focused on first in order to get the most out of the educational system.

\section{Method}

To ascertain the quality and efficiency of online teaching in Serbian higher education from the outbreak of the pandemic in March 2020 to December 2020, we conducted a two-phase research study based on collecting information from students:

- $\quad$ Phase I: a quantitative study

- $\quad$ Phase II: a qualitative study.

\section{Participants}

The sample for the quantitative study consisted of 211 students from the Faculty of Philosophy at the University of Niš, Serbia, whose attitudes were analysed in relation to their year of birth, year of study and average grade. We selected these students for two reasons. The first is that these students are currently studying to be future teachers, which means that they have knowledge of pedagogy, psychology and didactics. The second relates to the fact that the University of Niš completely reoriented its work to synchronous online teaching in a very short period of time. The university could therefore be considered an example of good practice and a suitable institutional context for researching emergency online teaching in higher education. The data were collected by providing students with a link to the research instrument digital technologies in the time of COVID-19 pandemic (DTPCO) assessement scale - which was distributed through the mediation of the Student Parliament and filled in anonymously. Students were 
reminded to fill in the instrument, which resulted in a final sample of 211 respondents. Therefore, it was a voluntary response sample.

The largest number of respondents (147) was aged between 19 and 22 (born between 1999 and 2002), 60 students were born between 1995 and 1998, and only 4 students were born between 1991 and 1994. When it comes to the year of study, the research included 26 students in first year, 72 students in second year, 63 students in third year and 50 students in fourth year of undergraduate academic studies. Concerning their academic achievement, three respondents had the lowest average grade (from 6.00 to 6.99), 44 students had an average grade between 7.00 and 7.99, 94 students had an average grade between 8.00 and 8.99 and 47 students had the highest average grade between 9.00 and 10.00. It is important to emphasise that out of 211 students, 188 of them provided responses regarding their academic achievement, bearing in mind that students in first year did not have final grades in their teaching courses.

The sample for the qualitative study consisted of 61 students in undergraduate and master academic studies in the Faculty of Philosophy at the University of Niš, who were invited to apply for and participate in an interview. The faculty mostly educates students for the teaching profession, which suggests the development of suitable didactic and methodological competencies. Of the respondents, 17 were in third year of undergraduate studies, 16 were in fourth year of undergraduate studies and 27 were master's students.

\section{Measures}

In the first research phase, we collected quantitative data through the use of the DTPCO assessment scale, a Likert-type assessment scale comprising 73 items. We constructed the scale for this research and delivered it to students by email at the end of the first semester; therefore, students had 1 month time to respond. The first part comprises 5 closed-ended questions relating to the demographic characteristics of the research sample. The second part is an assessment scale. In most of the items, we asked the students to choose an answer from 1 (I totally disagree) to 5 (I totally agree). For a small number of items, which examined the frequency of use of digital devices during the pandemic, the options were 1 (very frequently), 2 (frequently), 3 (occasionally), 4 (rarely), 5 (very rarely), 6 (not once) and 7 (I do not possess the stated device). It is important to emphasise that the DTPCO assessment scale has good reliability and internal agreement for this sample and Cronbach's alpha coefficient of 0.84 .

After processing the quantitative data and conducting the factor analysis, we assigned names to the factors according to the contents of the items that created the greatest loads within the selected components:

- Traditional vs online teaching

- Advantages/positive effects of digital applications used in online teaching

- Evaluation in online teaching

- The use of digital technology at the time of the pandemic outbreak and during the lockdown

- The disadvantages of online teaching

- The purpose of using digital devices

- The advantages of using Viber in online teaching.

These factors were the basis for creating the main questions and sub-questions for the interview we initiated in the second research phase - semi-structured online interview with 61 students via the Google Meet platform. The main questions were:

- How do you assess the quality of online teaching during the COVID-19 pandemic?

- How would you compare traditional and online teaching?

- How do you evaluate the application of various digital tools in teaching in the time after the outbreak of the pandemic to the present day?

- How do you assess the way in which professors evaluate and monitor student achievement in online teaching after the outbreak of a pandemic?

- How did you use digital devices (mobile phone, tablet, TV, laptop/desktop computer, etc.) that were available to you at home in the time after the outbreak of the COVID-19 pandemic and during curfew? 
- What bothers you the most in online work and why?

- What difficulties did you have in online teaching?

We added one more question relating to the second research task of the qualitative analysis (Do you prefer to have the camera of the professor or student presenting during lectures and tutorials turned on or off? Explain why.).

\section{Procedure}

The quantitative study, which was conducted in the period from May to June 2020, was preceded by a pilot study in April 2020 in order to examine the metric characteristics of the assessment scale. The qualitative study, which was conducted in November and December 2020, was preceded by a pilot study in October 2020 to verify the adequacy of the questions for the subsequent interviews.

Details of the two-phase research follow.

Phase I

The aim of Phase I was to establish the level of students' experiential knowledge of and attitudes on online teaching in higher education. We formulated the following research tasks:

(1) Reduce the initial set of variables by analysing the main components

(2) Establish if there are statistically significant differences between the selected factors and independent research variables

(3) Correlate the selected components to draw research inferences.

The DTPCO assessment scale aims to examine students' attitudes towards the use of digital technologies in the time of the pandemic. In the first phase of statistical data analysis, it was subjected to factor analysis to reduce the data to latent factors. To check the data adequacy for the analysis, we interpreted the value of the Kaiser-Meyer-Olkin (KMO) measure of sampling adequacy, whose border value should be higher than .600 as well as of Bartlett's test of sphericity, whose value should be statistically significant $(p<.050)$ (Kaiser, 1974). To define the number of selected factors, we resorted to the criteria of eigenvalue or characteristic root (eigenvalue) $\geq 1$ (Hair et al., 2019; Kaiser, 1960; Sharma, 1996). Since there is no unique or consistent interpretation of the value of the correlation coefficient in the literature (Overholser \& Sowinski, 2008), we decided to apply the correlation coefficient value interpretation by Cohen (1998, pp. 79-81). In this part of the research, the null hypothesis was set that there is no statistically significant correlation between the original variables (year of birth, year of study, average grade).

Phase II

Phase II comprised two or three semi-structured interviews lasting 30-45 minutes conducted in Serbian language via Google Meet. The interviews aimed to ascertain students' experiential knowledge more comprehensively by observing the quality of online teaching in undergraduate and master academic studies as a starting point for its further improvement. This comprised the following tasks:

(1) Establish students' perceptions of different indicators of the quality of online teaching (adaptations of students to the forced transition to online teaching, the quality of the applications used, the optimal requirements in teaching, the quality of monitoring student achievement and assessment and the contribution to the development of digital competencies in students).

(2) Establish students' attitudes towards the necessity of using cameras by either professors or students during lectures or tutorials and the reasons for those attitudes.

To secure a larger degree of objectivity in the process of data collection, we examined the students of those years of study to whom we had not previously given lectures. After previously obtaining students' consent, we recorded and subsequently transcribed the interviews, then processed the data using the suitable methodological approach recommended in reference literature (Dey, 1993; Griffee, 2005; Vogt et al., 2014). More precisely, we conducted deductive and inductive thematic analysis of the collected qualitative data. The theoretical findings constituted the basis for a deductive approach in the field of studying individual differences in students as well as the characteristics of online teaching and the higher education institution. On the other hand, we applied an inductive approach to refine the categories derived from theory 
and to identify new subcategories which had not previously been considered in the reference literature. We used the triangulation of researchers in order to increase objectivity in the course of processing, analysing and interpreting the collected qualitative data, while we chose the triangulation of methods (qualitative and quantitative) in order to observe the research problem more comprehensively. A large number of respondents were interviewed in order to obtain sufficient data to draw general research inferences. Upon going over the interview transcripts several times, we resorted to further processing. In the course of processing the collected qualitative data, we reached an agreement regarding the categories of analysis that were to be retained and processed further as well as the analysis and interpretation of data within identified categories.

\section{Results of factor analysis}

First and foremost, we intended to establish the justification to apply factor analysis in the statistical data processing. The values of the KMO measure of sampling adequacy as well as Bartlett's test of sphericity were calculated for that purpose. The KMO coefficient value was 0.830 , while the $p$ value of Bartlett's test of sphericity was statistically significant $(\chi 2=9032.131, p<.000)$. Therefore, the null hypothesis stating that there is no statistically significant correlation between the original variables (year of birth, year of study, average grade) was rejected. Bearing in mind the aforementioned, we can infer that conducting factor analysis was justified. Based on the calculated Kaiser-Guttman root one criterion, we decided to single out 18 components, that is, factors that explain $69.57 \%$ of the total variance.

In the course of research, we decided on conducting an overview of seven factors that explain almost 50\% of the total cumulative variance. The components were brought into Promax rotation and interpreted as linguistic and evaluative characteristics of words (Table 1). While conducting the factor analysis, we applied the Promax rotation, which served as the basis for obtaining the matrix of the structure of rotated factors, as the basis for further data analysis. Considering that we decided to select seven factors, in the course of further analysis of the research results, 13 items with double opposition were eliminated.

Table 1

Matrix of the structure of extracted factors

\begin{tabular}{|c|c|c|c|c|c|c|c|}
\hline \multirow[t]{3}{*}{ Component } & \multicolumn{7}{|c|}{ Total variance explained } \\
\hline & \multicolumn{3}{|c|}{ Initial eigenvalues } & \multicolumn{3}{|c|}{ Extraction sums of squared loadings } & \multirow{2}{*}{$\begin{array}{cc}\begin{array}{c}\text { Rotation sums } \\
\text { of squared } \\
\text { loadings }\end{array} \\
0 & \text { Total } \\
\end{array}$} \\
\hline & Total & $\%$ of variance & Cumulative \% & Total & $\%$ of varian & Cumulative \% & \\
\hline 1 & 14.963 & 20.497 & 20.497 & 14.963 & 20.497 & 20.497 & 10.332 \\
\hline 2 & 6.013 & 8.237 & 28.735 & 6.013 & 8.237 & 28.735 & 8.491 \\
\hline 3 & 4.989 & 6.835 & 35.569 & 4.989 & 6.835 & 35.569 & 5.258 \\
\hline 4 & 3.292 & 4.510 & 40.079 & 3.292 & 4.510 & 40.079 & 8.041 \\
\hline 5 & 2.683 & 3.675 & 43.754 & 2.683 & 3.675 & 43.754 & 7.696 \\
\hline 6 & 2.249 & 3.081 & 46.835 & 2.249 & 3.081 & 46.835 & 4.996 \\
\hline 7 & 1.981 & 2.714 & 49.549 & 1.981 & 2.714 & 49.549 & 4.500 \\
\hline 8 & 1.740 & 2.383 & 51.932 & 1.740 & 2.383 & 51.932 & 8.301 \\
\hline 9 & 1.637 & 2.243 & 54.175 & 1.637 & 2.243 & 54.175 & 3.029 \\
\hline 10 & 1.519 & 2.080 & 56.255 & 1.519 & 2.080 & 56.255 & 3.378 \\
\hline 11 & 1.503 & 2.058 & 58.314 & 1.503 & 2.058 & 58.314 & 3.475 \\
\hline 12 & 1.364 & 1.869 & 60.183 & 1.364 & 1.869 & 60.183 & 1.906 \\
\hline 13 & 1.308 & 1.791 & 61.974 & 1.308 & 1.791 & 61.974 & 2.495 \\
\hline 14 & 1.235 & 1.692 & 63.666 & 1.235 & 1.692 & 63.666 & 2.818 \\
\hline 15 & 1.168 & 1.600 & 65.266 & 1.168 & 1.600 & 65.266 & 1.860 \\
\hline 16 & 1.100 & 1.507 & 66.773 & 1.100 & 1.507 & 66.773 & 5.600 \\
\hline 17 & 1.033 & 1.415 & 68.187 & 1.033 & 1.415 & 68.187 & 2.208 \\
\hline 18 & 1.014 & 1.389 & 69.577 & 1.014 & 1.389 & 69.577 & 4.766 \\
\hline
\end{tabular}

The first factor, which we named Traditional vs online teaching, had a high factor load on 16 variables, and gathers those items relating to the comparison of traditional and online teaching. The second factor, which we named Advantages/positive effects of digital applications used in online teaching, had a positive factor load on 11 variables and gathered those items relating to the use of different digital applications in the teaching process from the outbreak of the pandemic to the present day. We named the third factor Evaluation in online teaching because it gathered those items relating to professors' evaluation of students' 
achievements in online teaching and had a positive factor load on 8 variables. The fourth factor had a positive factor load on 10 variables and based on the items' topic we named it The use of digital technology at the time of the pandemic outbreak and during the lockdown. The fifth factor had a high positive factor load on 6 variables; it gathered those items relating to the assessment of online teaching at the time of the pandemic; therefore, we named it The disadvantages of online teaching. We named the sixth factor The purpose of using digital devices because it gathered those items relating to the perceived purpose of digital technologies in education during pandemic and had a high positive factor load on 5 variables. We selected and named the last factor The advantages of using Viber in online teaching; it had a high factor load on 4 variables and gathered the items relating to the use of Viber (a calling and messaging app very popular in Serbia, similar to WhatsApp) in online teaching during the pandemic.

Table 2 shows the results for those factors in which there was a statistically significant difference in respondents' answers concerning independent variables at the applied level of statistical significance $p<$ 0.05. In Factor 3, only the year of study variable had a statistically significant impact on students' attitudes towards evaluation in online teaching (statistically significant differences were established in responses of students attending the first and third years of study). Concerning Factor 4, only the year of birth variable had a statistically significant impact on students' attitudes towards the use of digital technologies at the time of pandemic outbreak and lockdown (we established the differences in attitudes of students belonging to the oldest category of respondents, who were the most frequent users, and the students belonging to the youngest category, who were the least frequent users of the devices). Concerning Factor 6, students' attitudes towards the purpose of using digital devices were significantly influenced only by the year of birth and average grade variables. Concerning Factor 7, students' attitudes towards the advantages of using Viber in online teaching were significantly influenced only by the year of study variable.

Table 2

Statistically significant differences in students' responses concerning independent variables

\begin{tabular}{|c|c|c|c|c|c|c|c|}
\hline Factors & Variables & & $M$ & $S D$ & $F$ & $d f$ & $p$ \\
\hline \multirow{4}{*}{$\begin{array}{l}\text { Evaluation in online } \\
\text { teaching }\end{array}$} & \multirow[t]{4}{*}{ Year of study } & 1 & 25.538 & 3.701 & \multirow[t]{4}{*}{4.574} & \multirow[t]{4}{*}{3} & \multirow[t]{4}{*}{0.004} \\
\hline & & 2 & 28.000 & 3.673 & & & \\
\hline & & 3 & 28.873 & 4.386 & & & \\
\hline & & 4 & 27.300 & 4.136 & & & \\
\hline \multirow{3}{*}{$\begin{array}{l}\text { The use of digital } \\
\text { technology at the time of } \\
\text { the pandemic outbreak and } \\
\text { during the lockdown }\end{array}$} & \multirow[t]{3}{*}{ Year of birth } & 1991-1994 & 23.000 & 15.79 & \multirow[t]{3}{*}{10.382} & \multirow[t]{3}{*}{2} & \multirow[t]{3}{*}{0.00} \\
\hline & & 1995-1998 & 39.133 & 8.224 & & & \\
\hline & & 1999-2002 & 39.938 & 6.676 & & & \\
\hline \multirow{7}{*}{$\begin{array}{l}\text { The purpose of using } \\
\text { digital devices }\end{array}$} & \multirow[t]{3}{*}{ Year of birth } & 1991-1994 & 13.750 & 4.349 & \multirow[t]{3}{*}{4.754} & \multirow[t]{3}{*}{2} & \multirow[t]{3}{*}{0.010} \\
\hline & & 1995-1998 & 8.4667 & 3.196 & & & \\
\hline & & 1999-2002 & 8.5714 & 3.392 & & & \\
\hline & \multirow[t]{4}{*}{ Average grade } & $6.00-6.99$ & 8.6667 & 1.527 & \multirow[t]{4}{*}{3.693} & \multirow[t]{4}{*}{3} & \multirow[t]{4}{*}{0.013} \\
\hline & & $7.00-7.99$ & 9.5909 & 3.412 & & & \\
\hline & & $8.00-8.99$ & 8.8298 & 3.554 & & & \\
\hline & & $9.00-10.00$ & 7.3404 & 2.776 & & & \\
\hline \multirow{4}{*}{$\begin{array}{l}\text { The advantages of using } \\
\text { Viber in online teaching }\end{array}$} & \multirow[t]{4}{*}{ Year of study } & 1 & 13.923 & 2.018 & \multirow[t]{4}{*}{3.021} & \multirow[t]{4}{*}{3} & \multirow[t]{4}{*}{0.031} \\
\hline & & 2 & 12.222 & 2.541 & & & \\
\hline & & 3 & 12.920 & 2.610 & & & \\
\hline & & 4 & 12.200 & 3.545 & & & \\
\hline
\end{tabular}

Table 3 shows the correlation of selected components. Correlation is a measure of the relationship between two variables. A monotonous relationship between two variables is one in which an increase in the value of one variable signifies an increase in the value of the other variable or the relationship in which an increase in value of one variable signifies an decrease in value of the other variable. More precisely, higher values of the first variable tend to be connected either with higher (positive correlation) or lower (negative correlation) values of the other variable and vice versa. Several approaches were used to interpret the correlation as weak, moderate or strong. Although researchers would probably agree with the assertion that the coefficient $<0.1$ indicates negligible and $>0.9$ very strong correlation, the values in between are subject to interpretation. For instance, the correlation coefficient of 0.65 can be interpreted as a good or moderate correlation. Likewise, it is not appropriate to claim that the correlation coefficient of 0.39 is weak and that 
of 0.40 moderate correlation (Schober et al., 2018). The correlation coefficient ranges from -1 to +1 . The value -1 indicates perfect negative correlation (as variable 1 increases, variable 2 decreases). The perfect positive correlation has the correlation coefficient of +1 , while $\mathrm{r} 0$ signifies that there is no linear correlation.

Table 3

Pearson's correlation coefficient of selected factors

\begin{tabular}{|c|c|c|c|c|c|c|c|c|}
\hline Factors & & $\begin{array}{l}\text { Traditional vs } \\
\text { online } \\
\text { teaching }\end{array}$ & $\begin{array}{l}\text { Advantages of } \\
\text { digital } \\
\text { applications } \\
\text { used in online } \\
\text { teaching }\end{array}$ & $\begin{array}{c}\text { Evaluation in } \\
\text { online } \\
\text { teaching }\end{array}$ & $\begin{array}{c}\text { The use of } \\
\text { digital } \\
\text { technology at } \\
\text { the time of the } \\
\text { pandemic } \\
\text { outbreak }\end{array}$ & $\begin{array}{l}\text { Disadvantages } \\
\text { of online } \\
\text { teaching }\end{array}$ & $\begin{array}{c}\text { The purpose of } \\
\text { using digital } \\
\text { devices }\end{array}$ & $\begin{array}{l}\text { Advantages } \\
\text { of using } \\
\text { Viber in } \\
\text { online } \\
\text { teaching }\end{array}$ \\
\hline \multirow{2}{*}{$\begin{array}{l}\text { Traditional vs } \\
\text { online teaching }\end{array}$} & $\mathrm{r}$ & 1 & $.491^{* *}$ & $.302^{* * *}$ & -.119 & $-.359^{* *}$ & -.004 & $.243^{* *}$ \\
\hline & sig. (p) & & .000 & .000 & .085 & .000 & .957 & .000 \\
\hline \multirow{2}{*}{$\begin{array}{l}\text { Advantages of } \\
\text { digital } \\
\text { applications used } \\
\text { in online teaching }\end{array}$} & $r$ & $.491^{* * *}$ & 1 & $.499^{* * *}$ & -.020 & $-.345^{* *}$ & -.115 & .120 \\
\hline & sig.(p) & .000 & & .000 & .772 & .000 & .095 & .083 \\
\hline \multirow{2}{*}{$\begin{array}{l}\text { Evaluation in } \\
\text { online teaching }\end{array}$} & $\mathrm{r}$ & $.302^{* *}$ & $.499^{* *}$ & 1 & .021 & $-.220^{* *}$ & -.055 & $.149^{*}$ \\
\hline & sig. (p) & .000 & .000 & & .760 & .001 & .425 & .030 \\
\hline \multirow{2}{*}{$\begin{array}{l}\text { The use of digital } \\
\text { technology at the } \\
\text { time of the } \\
\text { pandemic } \\
\text { outbreak }\end{array}$} & $\mathrm{r}$ & -.119 & -.020 & .021 & 1 & $.144^{*}$ & $-.289^{* *}$ & -.132 \\
\hline & sig. (p) & .085 & .772 & .760 & & .036 & .000 & .055 \\
\hline \multirow{2}{*}{$\begin{array}{l}\text { Disadvantages of } \\
\text { online teaching }\end{array}$} & $\mathrm{r}$ & $-.359^{* *}$ & $-.345^{* *}$ & $-.220^{* *}$ & $.144^{*}$ & 1 & -.068 & .022 \\
\hline & sig. (p) & .000 & .000 & .001 & .036 & & .328 & .746 \\
\hline \multirow{2}{*}{$\begin{array}{l}\text { The purpose of } \\
\text { using digital } \\
\text { devices }\end{array}$} & $\mathrm{r}$ & -.004 & -.115 & -.055 & $-.289^{* *}$ & -.068 & 1 & -.035 \\
\hline & sig. (p) & .957 & .095 & .425 & .000 & .328 & & .618 \\
\hline \multirow{2}{*}{$\begin{array}{l}\text { Advantages of } \\
\text { using Viber in } \\
\text { online teaching }\end{array}$} & $\mathrm{r}$ & $.243^{* *}$ & .120 & $.149^{*}$ & -.132 & .022 & -.035 & 1 \\
\hline & sig.(p) & .000 & .083 & .030 & .055 & .746 & .618 & \\
\hline
\end{tabular}

Pearson's correlation coefficient showed that (a) the more positively students assessed online teaching, the more positively they assessed digital applications used in online teaching; (b) the more students believed that online teaching has more advantages than traditional teaching, the more positively they assessed professors' evaluation of their academic achievements in online teaching; (c) the more positively students assessed online teaching, the less they believed that such form of teaching has disadvantages; (d) the more positively students assessed online teaching, the more positively they assessed the advantages of using Viber in online teaching; (e) the more positively students assessed the benefits of digital applications used in online teaching, the more positively they assessed evaluation in online teaching; (f) the more positively students assessed the digital applications used in online teaching, the less they believed in disadvantages of online teaching; (g) the more positively students assessed the digital applications Meet, Zoom and Google Classroom, the more positively they assessed the use of Viber in online teaching; (h) the more satisfied students were with evaluation in online teaching, the less they believed that it has disadvantages; (i) the more positively students assessed the evaluation in online teaching, the more positively they assessed the use of Viber in online teaching; (j) the more frequently students used digital devices at the time of the pandemic outbreak, the more they believed that online teaching had disadvantages; $(\mathrm{k})$ the more students believed that online teaching has disadvantages, the more frequently they used digital devices at the time of lockdown for academic purposes as well as for entertainment; (l) the more students believed that online teaching has disadvantages, the more they believed that Viber has advantages and positive effects in online teaching. It is possible that students who generally use digital devices more frequently have more practical experience and a better understanding of the potential of their use. As a result, they observed the negative aspects of using digital tools in an online classroom more easily. Furthermore, it is quite possible that students' long daily exposure to digital devices in the course of the pandemic could have led to oversaturation. Likewise, it is also possible that some students required teaching approaches that differ from synchronous online teaching and that would be more suitable for their individual learning styles (eg., individual academic assignments, a more frequent use of Viber in online teaching). 


\section{Results of qualitative analysis}

\section{Quality indicators of online teaching}

We examined the quality of online teaching based on multiple indicators: students' adaptation to the emergency transition to online teaching, the quality of applications used, optimal requirements in the teaching process, the quality of monitoring and assessing students' achievements and contributing to the development of digital competencies in students. Contrary to Aguilera-Hermida's (2020) finding that students observed a reduction in the quality of higher education, the findings of our research suggest the opposite.

With regard to the students' adaptation to the emergency transition to online teaching, contrary to the Aguilera-Hermida's findings (2020) in the course of which students' saw emergency online teaching as an unpleasant experience, the findings of our research suggest the opposite. The largest number of students (39) described such teaching as a positive experience (e.g., "I found this to be a pleasant experience, rather than unpleasant. I believe that online teaching has more positive than negative sides in the case of social sciences and humanities."). Nine students explicitly stated that the quality of teaching was at a high level (e.g., "In my opinion, the quality of online teaching is quite high, and the transition from traditional to online teaching was not a problem in my case.") A significantly smaller number of students (14) described online teaching as an ambivalent experience (e.g., "The transition to online teaching was pleasant to some extent, but also unpleasant. Professors put maximum effort and this is the positive aspect of it all, but on the other hand this will never be as good as the classroom. Online teaching did not make some courses harder to attend. I did not feel that."). Only 8 students described online teaching as a negative experience (e.g., "The transition to online teaching was very stressful and unpleasant, because I had no idea if I was going to be able to adjust and get used to this way of working. In the beginning it was very strange to follow the lectures online, instead of in the classroom. Attending some courses became more difficult, because I get distracted at home, while in the classroom, I am focused and I participate in lectures and tutorials.”).

In the course of online teaching, Google Meet, Zoom and Google Classroom were used, and almost all students assessed them as highly efficient (e.g., "The combination of Google Meet, Zoom and Google Classroom appears to be ideal. The first two applications help us listen to the lectures and give presentations, while the latter helps us receive notifications and learning materials, pose questions and receive answers."). According to students, the most significant advantage of Zoom in comparison to Google Meet is the possibility of forming groups, which enables teachers who opted for this application to apply group work even during online teaching. The respondents emphasised that even though Viber has not been used in online teaching, it can by all means be considered an efficient application which could contribute to a much faster and timely communication between students and professors (e.g., "The main advantage of Viber would be the high frequency of use of this social network among students, which implies better communication.").

With regards to optimal requirements in online teaching, 23 respondents believed that teachers' requirements were realistic (e.g., "The transition to online teaching implies the change in teachers' requirements when it comes to working methods and our tasks, but the knowledge and specific criteria must not be reduced. From that standpoint, the requirements were realistic."). In contrast, 17 respondents assessed that teachers' requirements were not suitable (e.g., "Teachers' requirements were realistic with regards to complexity, but not with regards to the time necessary to complete them. There were situations when teachers believed that a task could be done in a matter of two or three hours, while in reality the majority of students needed two days.").

When it came to monitoring students' achievements and evaluation quality, over $90 \%$ of respondents (51) believed that teachers have suitably monitored their achievements and that they have been suitably evaluated after attending online teaching (e.g., "I believe that I was suitably evaluated during online teaching, in line with my efforts and commitment. The feedback was timely and adequate, as well as the evaluation."). Only 7 students assessed that their achievement was not monitored and evaluated properly (e.g., "I believe that in the course of online teaching professors did not have sufficient insight into our work, which could have made the evaluation far better. The evaluation criteria were different with every professor, and not all of them were objective. In the case of some courses students did not receive their test results on 
time."). A total of 18 students pointed out that evaluation criteria should have been relaxed, bearing in mind the circumstances, while 8 believed that this was not necessary.

With regards to the impact of online teaching on students' achievements, the majority (28) assessed that online teaching did not affect their achievement, that is, that they were equally successful as in traditional teaching; a smaller number of students (13) believed that their achievement was better because of online teaching, and only a few of them (3) believed that online teaching impeded their academic achievements. A total of 45 respondents believed that the additional positive outcome of online teaching was the development of digital competencies, while only 5 students believed that there was no such impact, assigning this to the previous experience of using different digital devices and applications.

\section{Positive and negative aspects of online and traditional teaching}

According to students, the advantages of online teaching were as follows: facilitated approach to teaching, that is, the ability to attend lectures from different places; the possibility of simultaneously performing other activities while attending the teaching process; the ability to establish better cooperation with some students; the ability to take the tests online (which facilitates evaluation and enables timely feedback to students); more time for studying and other activities, because time is not wasted on going to and coming back from the faculty; practical approach to explaining teaching content by means of online teaching; digital training of students; the use of different digital tools and technologies; a more flexible atmosphere; the possibility of a more careful individual class attendance than in the case of faculty teaching; the possibility of an innovative approach to higher education. A decrease in the costs of studies is an aspect frequently emphasised in literature dealing with online teaching (Kenzig, 2015; Littenberg-Tobias \& Reich, 2020).

In contrast, the disadvantages were as follows: students' passivity, that is, limited possibilities for their active participation in class; decreased possibilities for having discussion and intensive exchange of opinions in class; lack of interest in communicating with professors and colleagues; technical difficulties with digital devices and Internet issues and/or the loss of signal; social distance; frontal approach; spending too much time with digital devices, which causes health issues; lack of insight into students' attendance (because students do not turn on their cameras); lack of feeling of being a student, that is, perceiving online teaching as a form of informal education; lack of motivation and focus (students' attention is oriented towards some other things); lack of self-control; unequal access to digital technologies and conditions at home; not all students are comfortable with online communication; cold atmosphere in class; loss of time due to technical issues; increased stress and anxiety due to possible technical issues while presenting preexam tasks or listening to lectures; inability to perform practical activities; many issues that students encounter remain unanswered; workshop realisation is not possible online; the inability to develop important professional competencies which require immediate interaction; absence of non-verbal communication; lack of feedback to teachers about the level of understanding the content; lack of togetherness; insufficient preparedness of some teachers. Our findings with regards to the advantages and disadvantages of online teaching are similar to those findings of another research realised with almost the same goal (Hussein et al., 2020).

The advantages of traditional teaching which students consider important were direct contact with professors and colleagues; the ability to adequately monitor the understanding of teaching content, commitment and student achievement, which is the basis for individual teaching and evaluation (e.g., it is easier for teachers to gain insight into students' activities, into who attends the lectures, to encourage students to be more active); the possibilities of interaction between students and teachers as well as students with each other are significantly higher, which contributes to socialisation; equal opportunities for students to prove themselves (e.g., no overlapping of answers, no echo, no technical issues preventing active participation); the sense of obligation which makes one organise one's time better; focus and attention are better; the possibility of a two-way communication between teachers and students; the possibility of verbal and non-verbal communication; focus on lectures and tutorials; an encouraging ambiance; the possibilities of cooperative learning; the possibility of developing social, emotional and practical skills; greater possibilities for different activities; a more adequate evaluation of students' achievements and efforts; the possibility of working with realistic materials which makes the teaching more interesting and useful. 
In contrast, the disadvantages of traditional teaching were as follows: the possibility of physical presence in class, but not the spiritual one; long pauses between lectures; decreased use of digital technologies; formal atmosphere in class; too much energy and time wasted on preparation, arrival and departure; increased costs. Only two students believed that traditional teaching has no disadvantages.

As a positive experience of online teaching, one student stated that it was useful when some teachers recorded the lectures and made the recording available to other students, which facilitated the preparation for exams, while another student stated that such practice should be made obligatory. The availability of teaching materials through recorded lessons is an important aspect of online teaching (Hussein et al., 2020; Lapitan et al., 2021; Noetel et al., 2021).

After we surveyed students about their views on the potential of online and traditional teaching, we asked them to assess how teaching should be conducted in the future, after a pandemic. The largest number of students (18) gave preference to blended learning; some (6) believed that both forms of teaching should be run simultaneously, while students should be allowed to choose how they wish to learn; some students (4) believed that they should go back to traditional teaching, while the smallest number of students (3) gave preference to online teaching. Other respondents did not express a clear attitude.

\section{Most frequently encountered difficulties}

Difficulties encountered in online teaching were as follows: the lack of Internet connection or slow connection; the lack of a two-way communication, interaction, discussion, participation in class; the lack of additional explanations; spending too much time with digital devices; the lack of social contacts with colleagues and teachers; frontal approach to teaching which affects one's attention and focus; the request to turn the cameras on; an echo due to simultaneous reporting of several students; inadequate conditions at home; professors' inability to become better acquainted with students; overwhelming pre-exam obligations in case of various courses; subjectivity of various teachers in the process of evaluation; the lack of acknowledgement of students' activities in lectures and tutorials; technical issues with digital devices; the lack of cooperation among colleagues; the lack of technical possibilities for an active inclusion in the teaching process; long stay at home affecting motivation, attention and interests; the lack of direct contact with teachers and colleagues; the lack of closeness between colleagues and teachers; the fact that most students do something else while they allegedly attend the lectures; the absence of quality feedback from professors or the poor quality of such information; insufficient digital literacy of colleagues and professors; the lack of non-verbal communication; occasional power cuts; members of the household who interfered with school attendance; the lack of self-efficiency and self-control; sharing digital devices with siblings who also attend online teaching; other family obligations (baby in the house). Only three students stated that they had no interferences at all. Therefore, the things that interfered with students' online teaching were the same things they saw as disadvantages of such forms of teaching, which can be attributed to the way in which such teaching is realised, and not necessarily to the online teaching itself.

\section{Assessment of the need to turn on the cameras by professors and students alike}

The majority of students did not want to turn on their cameras during online teaching, which inspired us to examine students' attitudes in that respect as well as their arguments. The issue of regulating students' visibility to other colleagues and teachers is a feature of emergency online teaching (Hussein et al., 2020).

Regarding the results of our research, it is possible to distinguish between seven categories of responses:

- The camera should be turned on for all participants in the teaching process (e.g., "I believe that camera is essential during lectures and tutorials. Thus, we achieve better communication, and we are more active. It enables better monitoring of other students.").

- The professor's camera should be turned on, but not the students' (e.g., "I feel more comfortable when professor's camera is turned on. I find it easier to follow the lectures. As to students' cameras, I know how uncomfortable we feel and how nervous we are when we turn the cameras on. I believe that some students' presentations are greatly affected by cameras, though most professors would prefer to see when students speak."). 
- The camera does not have to be turned on for anybody (e.g., "During the class I prefer when the camera is turned off because the sound is much better and I can hear both professor and other students and the sound is not choppy, which helps me follow the lecture without interruption. I believe that cameras distract our attention.").

- Rules should be set that everyone will follow (e.g., "If the professor turns the camera on the students should do the same or they should establish the rule from the beginning and stick to it, if they can, of course.").

- The participants should be free to decide (e.g., "It would be preferable if everyone could decide for themselves whether to turn the camera on, because some students live in a small space with many family members.").

- Whether the camera will be turned on depends on the class activity (e.g., "I do not believe that camera is very important if there is a presentation. If there is no presentation the camera is important because of focus and it is better to see the person who talks than just to listen to him/her.").

- It is irrelevant whether the camera is turned on (e.g., "Bearing in mind that this is a new form of teaching and that we are just getting used to it (both students and professors), I find it irrelevant whether the camera is turned on or not.").

\section{Discussion and limitations}

The results of the research show that students hold in high esteem the quality of emergency online teaching. The general attitude is that, considering the circumstances, such teaching was the best possible solution, and the faculty was successful at making the transition. The fear of the unknown caused discomfort in students and teachers, but in time they managed to see the potentials of online teaching. It is possible that students expected online teaching to be much more complex and require highly developed computer skills, special tools and Internet connection, while in reality students were competent enough, and the digital tools and the Internet were quite sufficient to efficiently attend the classes (Hussein et al., 2020). Our finding that the majority of respondents prefer traditional teaching to online teaching is in accordance with the findings of Aguilera-Hermida (2020).

As to teachers, the results show that students are satisfied with how teachers responded to the new circumstances. Naturally, some teachers were less successful, which is the result of various individual and institutional factors that some teachers did not find suitable (Scherer et al., 2021). Therefore, it is essential to work on teachers' competencies for online teaching as well as to resort to blended learning (Kenzig, 2015; Qazi et al., 2020; Tynan et al., 2015). Teachers should make sure that all the benefits of the Internet, such as flexibility, are adequately used, while simultaneously devising strategies to develop students' selfregulation (Broadbent \& Poon, 2015).

Our findings based on qualitative research are in accordance with those of Qazi et al. (2020). This study was conducted at the outbreak of COVID-19. The findings show that the social context (developed countries as opposed to developing countries), the environment in which students live (related to Internet speed and stability as well as to the availability of digital devices and tools) and previous experience in using online resources influence the level of students' satisfaction with emergency online teaching. In research similar to ours (Hussein et al., 2020), students pointed out the following positive aspects of emergency online teaching: financial and temporal efficiency of such teaching, health security, the availability and improved participation. On the other hand, Hussein et al. found that distraction, poor focus, overwhelming pre-exam obligations, technological issues and weak and insufficient support from teachers and colleagues were the most frequently stated negative aspects of this form of teaching, and our findings are in agreement with this study.

In Aguilera-Hermida's (2020) research study, the majority of students did not experience the change in terms of grades during their online teaching. It does not appear that students' achievements are affected by the fact that they attend the lectures in person or online (Kinash et al., 2015). Some individual differences in terms of achievements in online teaching can be noted in Stöhr et al.'s (2020) research, where the authors state that some students can achieve better success in the online context, while for others such circumstances may seem unfavourable. Broadbent and Poon's (2015) research established that personal strategies for time 
management, metacognition, effort regulation and critical thinking are positively correlated with academic outcomes in online teaching.

Academic self-efficiency is an important variable of success in attending online teaching (Bravo-Agapito et al., 2021; Delnoij et al., 2020; Hong et al., 2021; Littenberg-Tobias \& Reich, 2020). On the other hand, the possibility (accessibility) of attending such classes at home can affect student self-regulation in online learning. Likewise, it is possible that students' negative attitude towards this form of learning can affect their academic achievements, and that such negative experience decreases their self-efficiency and motivation, which is an additional confirmation that online learning is not good for them. Thus, the cycle of negative expectations and experiences goes on (Aguilera-Hermida, 2020). Nevertheless, if a suitable number of digital tools and devices as well as suitable institutional practices are secured in online teaching, it is possible to significantly improve educational outcomes in students from different social backgrounds (Edmunds et al., 2021).

The absence of interaction or insufficient interaction has been pointed out as a significant disadvantage of emergency online teaching, which can decrease students' motivation (Aguilera-Hermida, 2020), due to the tediousness of such teaching and the lack of possibility to realise social contact with others. Therefore, teachers should take into account the psychological needs of students (to belong, to socialise) in the process of online teaching, considering that students' engagement in online teaching will depend on their perception as to how much their psychological needs are satisfied in such a context (Shah et al., 2021; C. Wang et al., 2019). It is possible to conduct interactive online classes in higher education with the adequate use of available digital tools (Kahoot!, Menti, Google Sheets, Google Workspace) as well as organising different types of cooperative teaching (Y.-H. Wang, 2020). It requires the adequate preparation of teachers and students. Cooperative learning can be an important factor for success in online teaching. Hence, encouraging peer learning in the context of online teaching can be a useful strategy (Broadbent \& Poon, 2015).

Even distraction as a frequently stated feature of online teaching is something that students and teachers can suitably handle. There are more efficient ways of decreasing the distraction of students in online teaching, one of which is pre-testing (Pan et al., 2020).

The largest number of respondents recognised that by resorting to blended learning students and teachers can overcome unfavourable aspects of online and traditional teaching and use their potential. Such teaching is especially suitable in institutions such as the University of Niš. Blended learning contributes to the improvement of learning in students of humanities, probably because of the communication aspects in the learning process, which are essential for the given field (Larionova et al. 2018). Students who attended blended learning had higher grades than students who attended traditional teaching (Littenberg-Tobias \& Reich, 2020). Introducing blended learning entails different phases to create the conditions for more efficient use of its potential to achieve a quality higher education, which results in a high level of students' activity (Park et al., 2016).

Our research has several limitations. First and foremost, the fact that the quantitative research was not conducted on a larger sample (due to the lack of interest in students to participate in an online survey) has probably influenced the research findings. Likewise, a different approach to qualitative research (focus groups) could have contributed to collecting somewhat different data. However, bearing in mind the circumstances we all have been living in for a year, researching in this manner could be considered an acceptable way of gathering empirical data. Students' and teachers' satisfaction is considered an important factor of online teaching quality. Therefore, it is important and necessary to continuously evaluate the extent to which it is present to secure quality online education (Bolliger \& Wasilik, 2009). Furthermore, the research examined only students' perceptions, which could have caused partiality in responding. Further research with a different methodology is needed.

\section{Conclusion}

The outbreak of the pandemic was a sudden life circumstance which changed the social context overnight and forced higher education institutions to turn to emergency online teaching. In this research, we examined how successful the Faculty of Philosophy at the University of Niš was in this process, further directions in the development of higher education as well as general inferences from the findings. The results of the 
quantitative analysis show that the statistically significant difference with respect to students' attitudes towards various aspects of the realised online teaching can be found when these variables were considered: year of study, the year of birth and the average grade during the studies. Furthermore, students' positive perceptions of certain aspects of online teaching are related to positive perceptions of the digital applications, the professors' evaluation of achievements in online teaching, the perception of advantages of online teaching in comparison to traditional teaching. The negative perceptions were related to excessive use of digital devices at the time of the pandemic as well as to the perception of the advantages of using Viber in online teaching in comparison to other devices. Thus, not all students were equally successful at adjusting to the newly established educational context. Future research studies should provide more detailed answers with respect to students' needs regarding the creation of a suitable teaching context.

With regard to the qualitative analysis, the quality of online teaching was at a satisfactory level. We used the following assessments in the analyses as quality indicators: students' adjustment to emergency online teaching, the quality of used applications, optimal requirements in teaching, the quality of monitoring students' achievements and assessments, and contribution to the development of digital competencies in students. Students have positively assessed digital devices used in online teaching, and they identified a series of advantages and disadvantages of both online and traditional teaching, indicating the most frequently encountered difficulties. Likewise, they presented different attitudes and different arguments for and against using cameras by students and professors in online teaching. Therefore, although students' assessments testify to the high quality of the realised online teaching, not all students adjusted to the newly introduced circumstances with equal efficiency, and there is still room for improvement. Online experiences have confirmed the importance of appropriate preparation for responding to unpredictable situations and adapting teaching to ensure the quality of education.

\section{Implications}

Our research has several implications. The theoretical implications are reflected in the acquired knowledge about experiences in organising online teaching in emergency situations such as the pandemic. Namely, the findings that the entire teaching process can be organised online and that interaction plays an important role constitute a starting point for future research studies into the theory and practice of online teaching. Future research studies should pay special attention to the individual characteristics of teachers and students, which can affect adjustment to and perceptions of online teaching, with the aim of adjusting this kind of teaching to the individual needs and specific learning styles of all students.

The practical implications are related to the advantages and disadvantages of online teaching, which can lead to devising a new model of teaching based on organising different types of higher education (traditional, online, blended teaching) and using the positive aspects of all these teaching models. It is possible to obtain this goal in the present circumstances, with the current experience in online teaching. However, it is necessary to secure adequate conditions to guarantee the quality of a teaching process. It is necessary to secure the quality of education with the suitable preparation of students and teachers at an institutional level. Furthermore, it is necessary to secure a suitable level of institutional support, to maintain the quality of online education. To prevent negative effects of online teaching on students' achievements, it is necessary to take into account individual differences and students' psychological needs (for belonging, socialising, cooperation) as well as to secure a suitable level of interaction among students. Moreover, a continuous formative and summative evaluation of online teaching is required at an institutional level as a basis for its further improvement while respecting the specifics of the institution itself.

Education policy implications are related to the necessity of devising a national strategy for the development of higher education in terms of introducing online and blended teaching. The strategy should also provide a set of guiding principles regarding the adequate application of digital tools in higher education. The necessary conditions for such actions are as follows: enacting appropriate legislation at a national level, organising different forms of professional development in teachers' digital competencies, securing funding to introduce innovation in teaching practice as well as securing the adequate infrastructure. It is necessary to exchange experiences at an interinstitutional and international level as well as to conduct continuous evaluation of its successful implementation at a national level while providing suitable support to higher education institutions. 


\section{Acknowledgements}

This study was supported by the Ministry of Education, Science and Technological Development of the Republic of Serbia (Contract No. 451-03-9/2021-14/200165).

\section{References}

Aguilera-Hermida, A. P. (2020). College students' use and acceptance of emergency online learning due to COVID-19. International Journal of Educational Research Open, 1, 1-8. https://doi.org/10.1016/j.ijedro.2020.100011

Bolliger, U. D., \& Wasilik, O. (2009). Factors influencing faculty satisfaction with online teaching and learning in higher education. Distance Education, 30(1), 103-116. https://doi.org/10.1080/01587910902845949

Bravo-Agapito, J., Romero, J. S., \& Pamplona, S. (2021). Early prediction of undergraduate student's academic performance in completely online learning: A five-year study. Computers in Human Behavior, 115, 1-11. https://doi.org/10.1016/j.chb.2020.10659

Broadbent, J., \& Poon, L. W. (2015). Self-regulated learning strategies \& academic achievement in online higher education learning environments: A systematic review. The Internet and Higher Education, 27, 1-13. https://doi.org/10.1016/j.iheduc.2015.04.007

Cohen, J. (1988). Statistical power analysis for the behavioral sciences (2nd ed.). Lawrence Erlbaum Associates.

Crawford-Ferre, H. G., \& Wiest, L. R. (2012). Effective online instruction in higher education. Quarterly Review of Distance Education, 13(1), 11-14. https://www.infoagepub.com/qrdeissue.html? $\mathrm{i}=\mathrm{p} 54 \mathrm{c} 3 \mathrm{c} 5059 \mathrm{aa} 7 \mathrm{c}$

Delnoij, C. E. L., Dirkx, H. J. K., Jose P.W. Janssen, W. P. J., \& Martens, L. R. (2020). Predicting and resolving non-completion in higher (online) education - A literature review. Educational Research Review, 29, Article 100313. https://doi.org/10.1016/j.edurev.2020.100313

Dey, I. (1993). Qualitative data analysis: A user-friendly guide for social scientists. Routledge.

Edmunds, A. J., Gicheva, D., Thrift, B., \& Hull, M. (2021). High tech, high touch: The impact of an online course intervention on academic performance and persistence in higher education. The Internet and Higher Education, 49, 1-10. https://doi.org/10.1016/j.iheduc.2020.100790

Fish, W. W., \& Wickersham, L. E. (2009). Best practices for online instructors: Reminders. Quarterly Review of Distance Education, 10(3), 279-284. https://www.infoagepub.com/qrdeissue.html? $\mathrm{i}=\mathrm{p} 54 \mathrm{c} 3 \mathrm{c} 79 \mathrm{e} 58 \mathrm{cb} 3$

Griffee, D. T. (2005). Research tips: Interview data collection. Journal of Developmental Education, 28(3), 36-37.

Hair, J. F., Jr., Black W. C., Babin, B. J.., \& Anderson, R. E. (2019). Multivariate data analysis (8th ed.). Cengage EMEA.

Herrera-Pavo, A. M. (2021). Collaborative learning for virtual higher education. Learning, Culture and Social Interaction, 28, Article 100437. https://doi.org/10.1016/j.lcsi.2020.100437

Hong, J.-C., Lee, Y.-F., \& Ye, J.-H. (2021). Procrastination predicts online self-regulated learning and online learning ineffectiveness during the coronavirus lockdown. Personality and Individual Differences, 174, Article 110673. https://doi.org/10.1016/j.paid.2021.110673

Hussein, E., Daoud, S., Alrabaiah, H., \& Badawi, R. (2020). Exploring undergraduate students' attitudes towards emergency online learning during COVID-19: A case from the UAE. Children and Youth Services Review, 119, Article 105699. https://doi.org/10.1016/j.childyouth.2020.105699

Kaiser, H. F. (1960). The application of electronic computers to factors analysis. Educational and Psychological Measurement, 20(1), 141-151. https://doi.org/10.1177\%2F001316446002000116

Kaiser, H. F. (1974). An index of factorial simplicity. Psychometrika, 39, 31-36. https://doi.org/10.1007/BF02291575

Kenzig, M. J. (2015). Lost in translation: Adapting a face-to-face course into an online learning experience. Health Promotion Practice, 16(5), 625-628. https://doi.org/10.1177/1524839915588295

Kerr, S. M., Rynearson, K., \& Kerr, C. M. (2006). Student characteristics for online learning success. The Internet and Higher Education, 9(2), 91-105. https://doi.org/10.1016/j.iheduc.2006.03.002

Kinash, S., Knight, D., \& McLean, M. (2015). Does digital scholarship through online lectures affect student learning? Educational Technology \& Society, 18(2), 129-139. https://drive.google.com/file/d/1qSmCXu3ZtdNR8WAaNbo1sn9BzHBN4mRO/view 
Lapitan, L. D. S., Jr., Tiangco, C. E., Sumalinog, G. A. D., Sabarillo, N. S., \& Diaz, J. M. (2021). An effective blended online teaching and learning strategy during the COVID-19 pandemic. Education for Chemical Engineers, 35, 116-131. https://doi.org/10.1016/j.ece.2021.01.012

Larionova, V., Brown, K., Bystrova, T., \& Sinitsyn, E. (2018). Russian perspectives of online learning technologies in higher education: An empirical study of a MOOC. Research in Comparative and International Education, 13(1), 70-91. https://doi.org/10.1177/1745499918763420

Littenberg-Tobias, J., \& Reich, J. (2020). Evaluating access, quality, and equity in online learning: A case study of a MOOC-based blended professional degree program. The Internet and Higher Education, 47, 1-11. https://doi.org/10.1016/j.iheduc.2020.100759

Milićević, V., Denić, N., Milićević, Z., Arsić, Lj., Spasić-Stojković, M., Petković, D., Stojanović, J., Krkić, M., Sokolov Milovančević, N., \& Jovanović, A. (2021). E-learning perspectives in higher education institutions. Technological Forecasting and Social Change, 166(11), 1-5. https://doi.org/10.1016/j.techfore.2021.120618

Money, H. W., \& Dean, P. B. (2019). Incorporating student population differences for effective online education: A content-based review and integrative model. Computers and Education, 138(1), 57-82. https://doi.org/10.1016/j.compedu.2019.03.013

Noetel, M., Griffith, S., Delaney, O., Sanders, T., Parker, P., del Pozo Cruz, B., \& Lonsdale, C. (2021). Video improves learning in higher education: A systematic review. Review of Educational Research, 91(2), 204-236. https://doi.org/10.3102/0034654321990713

Overholser, B. R., \& Sowinski, K. M. (2008). Biostatistics primer: Part 2. Nutrition in Clinical Practice, 23(1), 76-84. https://doi.org/10.1177/011542650802300176

Pan, S. C., Sana, F., Schmitt, A. G., \& Bjork, E. L. (2020). Pretesting reduces mind wandering and enhances learning during online lectures. Journal of Applied Research in Memory and Cognition, 9(4), 542-554. https://doi.org/10.1016/j.jarmac.2020.07.004

Park, Y., Yu, J. H., \& Jo, I. H. (2016). Clustering blended learning courses by online behavior data: A case study in a Korean higher education institute. The Internet and Higher Education, 29(1), 1-11. https://doi.org/10.1016/j.iheduc.2015.11.001

Qazi, A., Naseer, K., Qazi, J., AlSalman, H., Naseem, U., Yang, S., Hardaker, G., \& Gumaei, A. (2020). Conventional to online education during COVID-19 pandemic: Do develop and underdeveloped nations cope alike. Children and Youth Services Review, 119, Article 105582. https://doi.org/10.1016/j.childyouth.2020.105582

Scherer, R., Howard, K. S., Tondeur, J., \& Siddiq, F. (2021). Profiling teachers' readiness for online teaching and learning in higher education: Who's ready? Computers in Human Behavior, 118, Article 106675. https://doi.org/10.1016/j.chb.2020.106675

Schober, P., Boer, C., \& Schwarte, L. A. (2018). Correlation coefficients: Appropriate use and interpretation. Anesthesia and Analgesia, 126(5), 1763-1768. https://doi:10.1213/ANE.0000000000002864

Shah, S. S., Shah, A. A., Memon, F., Kemal, A. A., \& Soomro, A. (2021). Online learning during the COVID-19 pandemic: Applying the self-determination theory in the 'new normal'. Revista de Psicodidáctica, 26(2), 168-177. https://doi.org/10.1016/j.psicoe.2020.12.003

Sharma, S. (1996). Applied multivariate techniques. John Wiley and Sons, Inc.

Stöhr, C., Demazière, C., \& Adawi, T. (2020). The polarizing effect of the online flipped classroom. Computers \& Education, 147, Article 103789. https://doi.org/10.1016/j.compedu.2019.103789

Tynan, B., Ryan, Y., \& Lamont-Mills, A. (2015). Examining workload models in online and blended teaching. British Journal of Educational Technology, 46(1), 5-15. https://doi.org/10.1111/bjet.12111

Vogt, W. P., Gardner, D. C., Haeffele, L. M., \& Vogt, E. R. (2014). Selecting the right analyses for your data: Quantitative, qualitative, and mixed methods. Guilford Publications.

Wang, C., Hsu, K. H.-C., Bonem, M. E., Moss, D. J., Yu, S., Nelson, B. D., \& Levesque-Bristol, C. (2019). Need satisfaction and need dissatisfaction: A comparative study of online and face-to-face learning contexts. Computers in Human Behavior, 95, 114-125. https://doi.org/10.1016/j.chb.2019.01.034

Wang, Y.-H. (2020). Design-based research on integrating learning technology tools into higher education classes to achieve active learning. Computers \& Education, 156, Article 103935. https://doi.org/10.1016/j.compedu.2020.103935 
Corresponding author: Marija Markovic, marija.markovic@filfak.ni.ac.rs

Copyright: Articles published in the Australasian Journal of Educational Technology (AJET) are available under Creative Commons Attribution Non-Commercial No Derivatives Licence (CC BY-NC-ND 4.0). Authors retain copyright in their work and grant AJET right of first publication under CC BY-NC-ND 4.0 .

Please cite as: Marković, M., Pavlović, D., \& Mamutović, A. (2021). Students' experiences and acceptance of emergency online learning due to COVID-19. Australasian Journal of Educational Technology, 37(5), 1-16. https://doi.org/10.14742/ajet.7138 